\title{
Violence and Motherhood: A Case Study about the Personality Profile and Attachment Style of a Filicide Woman
}

\author{
Nicoletta Giacchetti, Corinna Pancheri, Riccardo Williams, Michela Marconi, \\ Rosa Magistro, Luciano Pozzuoli \& Franca Aceti
}

To cite this article: Nicoletta Giacchetti, Corinna Pancheri, Riccardo Williams, Michela Marconi, Rosa Magistro, Luciano Pozzuoli \& Franca Aceti (2019): Violence and Motherhood: A Case Study about the Personality Profile and Attachment Style of a Filicide Woman, Deviant Behavior, DOI: 10.1080/01639625.2019.1581000

To link to this article: https://doi.org/10.1080/01639625.2019.1581000

曲 Published online: 20 Feb 2019.

Submit your article to this journal ๘

View Crossmark data $\asymp$ 


\title{
Violence and Motherhood: A Case Study about the Personality Profile and Attachment Style of a Filicide Woman
}

\author{
Nicoletta Giacchetti ${ }^{a}$, Corinna Pancheri ${ }^{a}$, Riccardo Williams ${ }^{a}$, Michela Marconi ${ }^{b}$, \\ Rosa Magistro ${ }^{\mathrm{b}}$, Luciano Pozzuoli $^{\mathrm{b}}$, and Franca Aceti $^{\mathrm{a}}$ \\ aPoliclinico Umberto I of Rome, La Sapienza University of Rome, Rome, Italy; ${ }^{b}$ Asl Frosinone, Frosinone, Italy
}

\begin{abstract}
Several studies focused on mothers' psychopathological and environmental risk factors linked to filicide, but few studies explored personality characteristics of these women. Considering that the transition to motherhood requires the activation of deep personality resources, aim of this report is to describe the personality profile and attachment style of a woman who killed her 5-year-old son and tried to kill her 3-months-old daughter. The woman was assessed using Structured Clinical Interview for DSM-IV Axis I (SCID-I), Graphical Tests, Big Five Inventory (BFI), Temperament and Character Inventory (TCl), Adult Attachment Interview (AAI) and Minnesota Multiphasic Personality Inventory-2 (MMPI-2). Test results showed a profile characterized by emotional instability, inner fragility and tendency to experience negative emotions, with the possibility of apparently unmotivated hostile behaviors and a tendency towards complacency. AAl results showed a distancing attachment style shading light into the importance of the internalized maternal figure. Examining the mother's mental state, with attention on personality traits and attachment style, could help clinicians to detect specific temperament patterns that may carry out violent behaviours.
\end{abstract}

ARTICLE HISTORY

Received 29 October 2018

Accepted 7 February 2019

\section{Introduction}

Epidemiological data on deaths in infancy and childhood estimate that parents are responsible for more than half of the murders (Wolkind et al. 1993). Among the other causes of death, filicide rate ranges from 2-10\% (Craig 2004), even though a correct estimation of such episodes is difficult to achieve because they are often underestimated and miscategorised by other causes of death (UNICEF 2003). Whereas during the first year after birth murders (i.e. filicides) are mostly committed by the mothers, during later infancy it is the fathers who are more frequently involved in filicide (Bourget, Grace, and Whitehurst 2007). Concerning the offspring killings committed by the mothers, a difference based on the infant's age has been found: whereas neonaticides (i.e. the murder within the first 24 hours of life) are enacted on impulse and mostly by women with socioeconomic difficulties and without a history of any psychiatric diagnosis, filicides are mostly premeditated (Craig 2004; Huchzermeier and Heinzen 2015; Porter and Gavin 2010; Putkonen et al. 1998; Resnick 1970; Şar et al. 2017; Spinelli 2001). A recent study found that the mean age of child victims of mothers found not guilty by reason of insanity in two states was older than 3 years (Friedman et al. 2005a). In filicide, factors resulted as claiming cumulative interactions in the homicides are the presence of a psychiatric history, a dysfunctional attachment style and some socioeconomic factors (i.e. economic difficulties, conflicts within the couple, lack of prenatal care). Indeed, a high level of stress, associated with a lack of any psychological or emotional support, is frequently reported at the

CONTACT Corinna Pancheri corinnapancheri@hotmail.it $\Theta$ Department of Human Neuroscience, Policlinico Umberto I of Rome, La Sapienza University of Rome, Viale dell'Università 30, Rome 00185, Italy

Color versions of one or more of the figures in the article can be found online at www.tandfonline.com/udbh. 
moment of the murder. High rates of conflicts in long-term relationships/marriages were also described, as well as disagreements with the family of origin (Barone et al. 2014; Bourget, Grace, and Whitehurst 2007; Camperio Ciani and Fontanesi 2012; Friedman, Horwitz, and Resnick 2005; Friedman and Resnick 2007; Grussu 2012; Lewis and Bunce 2003; McKee and Bramante 2010; Resnick 1969).

The most relevant mental conditions connected with infant murders are psychosis and anxiety/mood disorders (Friedman, Horwitz, and Resnick 2005). Given that some new mothers with depression report intrusive and obsessive thoughts about being able to harm their child, this personal emotional condition is usually limited to the only fear of hurting the newborn (Gale and Harlow 2003). As a matter of fact, it should be noted that up to $20 \%$ of women present some kind of mood disorders after the birth of a child, but just a few of them commit filicide (Born, Zinga, and Steiner 2004). Instead, severe psychotic depression can bring a higher risk of suicide and infanticide (Riecher-Rössler and Fallahpour 2003). In a study by Lewis and Bunce (Lewis and Bunce 2003) of 55 filicidal women, 52.7\% were psychotic. However, it should be considered that puerperal psychosis affects only $1-2 \%$ of the female population, and just $4 \%$ of these women, if untreated, would eventually commit infanticide (Altshuler, Hendrick, and Cohen 1998). Personality disorders resulted to be frequently present among these women (Friedman et al. 2005b). Lewis (Lewis and Bunce 2003) reported a prevalence of diagnoses of personality disorders (67\%), compared to other psychiatric syndromes. Personality disorders may represent a diathesis of vulnerability during the postnatal period or during the offspring's growth, leading to the development of depressive episodes, often detected at the moment of infant murders (Aceti et al. 2012a, 2012b; Giacchetti et al. 2018; Meuti et al. 2014). Specifically, an increased risk of affective disorders during the first year after birth seems to be related to specific personality traits, especially neuroticism and introversion (Kendler et al. 2006; Podolska et al. 2010). In the neurotic personality, the management of stressful events and adaptive mechanisms seems compromised because of emotional instability and a generalized tendency to experience negative emotions. It is interesting to note that previous studies demonstrated that victims of abuse may become violent themselves, and that filicidal women more often experienced victimization in childhood than their male counterparts and other maternal child killers (Debowska, Boduszek, and Dhingra 2015). However, the presence of a psychiatric diagnosis during the peri-partum period, a neurotic and introverted personality trait or victimization in childhood and the consequent affective failure, do not seem enough to justify the violent act accomplished.

The current case report aims to explore the psychopathological and personality features of a woman who committed filicide through the analysis of the story, the clinical interviews and the personality assessment battery tests.

\section{Clinical case}

Alice is a 35-year-old woman of Ukrainian origin who has lived in Italy since the age of 20.

First born of 3, she has a 30-year-old brother who lives in Italy and a 28 -year-old sister who has remained in Ukraine, where her parents also live. The sister, married and employed, would be affected by an unspecified psychosis, and is treated with medicines. Alice's mother is 55 years old, and the year before patient was born she lost a child in the fifth month of pregnancy due to unspecified reasons. She is suffering from schizophrenia and epilepsy. She worked as a clerk until the birth of the second child.

The patient remembers seeing for the first time, at the age of 5, a psychotic crisis of her mother during a baptism party. The mother would have started screaming, yelling that the end of the world was imminent and that she had to go to the moon to save herself. On that occasion the patient's mother was admitted to a psychiatric hospital, and over the years many other events like this had followed, because of the woman's poor compliance with the prescribed therapies (she "wanted to be like the others" and "drink a little wine every now and then"). Actually, other admissions were often necessary due to her numerous suicidal attempts. Alice remembers the separation from her mother, whom she describes as a "sweet, helpful, generous person", as very distressing. 
Alice's father, a 59-year-old man, works as a soldier. The patient claims to be very attached to him. She remembers that he spent most of his time away from home and that he was often accused by her maternal grandmother for dating other women. Alice, despite having felt a deep anger towards him for this reason, claims to have appreciated the fact that he remained at home despite all the difficulties in the management of the family caused by her mother. The patient describes her father as "detached, overbearing, authoritarian but sometimes also kind". She had the feeling that her father preferred his son to her. She remembers with sadness that, as a child, she had feared more than once that she had been adopted.

The patient lived at her maternal grandparents' home until the age of 10 . Her house was, in fact, adjacent to that of her grandparents, both arranged along a river, surrounded by greenery, in a small village. She describes this place with great pleasure, outlining it like the country of a fairy tale and fondly remembers the maternal grandmother who, she claims, worked very hard for her growth.

The patient attended a language-oriented high school with good performance, but her whole scholastic path is remembered as rather "tiring" as regards the relationship with peers. Alice, in fact, was often made fun of for the unusual behaviour of her mother, which she herself did not understand the sense of, and was ashamed, showing a shy and introverted attitude towards others. At 19, she met her current husband, Gregorio, a man who is now 38 and works as an engineer. When Alice was 20, they decided to move to Italy. After 3 years, she returned to Ukraine and got married. She remembers proudly the whole organization of her marriage, since all the people who knew her emphasized how positively she had changed: from the shy, sad, introverted girl they had met, Alice had become a more cared-for woman, apparently self-confident, independent in her decisions. Marriage is strongly opposed by the family of origin of the husband, due to her familiarity with psychiatric disorders. Alice, at the request of her husband and her family, made a series of medical checks before marriage, including DNA testing. The patient describes her husband as a selfish person, not very sensitive, inclined to impose his point of view so much as to define him "the philosopher", for the tendency to argue his every decision and to convince the interlocutor of whatever he claims.

In Italy, the patient has worked as a domestic assistant and baby sitter, trusting in the emotional support of a couple of her uncles living in the same city. She describes as difficult the relations with the family of origin of her husband, which had moved to Italy at the same time. In particular, Alice has always felt as highly intrusive the figure of the mother-in-law, with whom the husband has a relationship, she says, of strong dependence. The mother-in-law, with a pretext, lived in their house for several months before and up to the birth of her first child, Giorgio, which occurred when the patient was 30 years old. Alice has had to fight decisively so that her mother-in-law would return to her home, located not far away.

The year before the birth of George, the patient had lost a child at the 6th month of pregnancy due to a severe kidney malformation. At the age of 32 she had a miscarriage, and when she was 34 Greta was born. The patient reports that this pregnancy was not planned, but took place without major problems. Immediately after the birth of Greta, the patient felt particularly anxious, in trouble at creating a relationship with her daughter, "as if she did not belong to her". During the first month of life, she had tried to breastfeed her, but she had little milk. She was advised, however, to continually try to breastfeed her, even at night, waking up the baby if she was asleep. Given the difficulties, the second month she introduced artificial feeding, successfully. Greta is described as a very quiet child, but the patient remembers that at that time she felt very lonely and tired. She struggled to take care of her children and of the house, all tasks that she continued to perform with dedication, despite the impression that she was "a robot".

Two weeks before the filicide, Alice had organized a birthday party for Giorgio, who had invited some classmates. She remembers having organized everything with great effort, despite the help of her husband. After this event, the patient's state of anguish deteriorated to such an extent that Alice began to feel "strange" and to consider as "alien" the surrounding environment. She was led by her husband to the mental health outpatient clinic and on that occasion she was prescribed Risperidone, a drug that the patient didn't approve for the assonance of the name of the drug with the word "lost" 
[Italian meaning: lost = "persa", thus is associated with Risperidone], as in a sort of delusional intuition. As she left the clinic, the patient called her father asking for forgiveness, a behaviour that her mother often had with her father before starting to speak. The patient can not explain why she did it.

The patient will discontinuously take the drug for a few days. In the meantime she developed the conviction that the end of the world is approaching and that, in order not to see her children suffering in an atrocious way, it was necessary to first kills them and then herself. She often speaks of a "hell on earth" and cannot see any alternative solution. In the days before the filicide, she repeatedly read a prayer book from which she deduced associations between the three "G" (initials of the names of the husband and children) and the three 6s (666), the number linked to Satan. On the morning of the murder, after her husband left home to go to work, the patient took 3-month-old Greta and drowned her in the bathtub under Giorgio's eyes. She then tried to do the same with him but it didn't work, as he was frightened and resisted. In order to reassure him, Alice offered him to drink some milk with drops of a powerful poison. Both the child and herself took a few sips.

Giorgio, after a week of resuscitation, survived and now lives with his father. The patient, who reported a lighter poisoning, was hospitalized in an acute psychiatric ward and then transferred to a forensic psychiatric hospital, diagnosed with "Bipolar affective syndrome, severe depressive episode, with psychotic behaviour, in complete remission (ICD IX: 296.54)". Currently she is taking therapy with Valproic Acid $800 \mathrm{mg} /$ day; Aripiprazole $10 \mathrm{mg} /$ day. She attributes the gesture to the "illness", an element that allows her to manage the sense of guilt in order to leave room for experiences of regret and sadness for having destroyed a condition of life in which she had what she wanted, even if she recognizes that the relationship with the husband had long become unsatisfactory. She has recurring thoughts about her daughter, of whom she remembers the "beautiful moments", often calling her "angel". She recently said that she always felt that her daughter was not destined to live, and that she had not been strong enough to oppose it.

In the months following the murder, Alice made regular interviews with a psychologist, during which she appears rigid and coerced, even if always submissive and collaborative. Spontaneously, however, she does not request support interviews but only information, and during the meetings, independently, does not report any specific topic.

Eye contact is maintained, as well as a sufficiently rich and varied conversation. In moments of greater emotional contact, the patient misdirects the gaze, remains silent and tightens her mouth more strongly. The intense emotional experience of anger and sadness is hardly tolerated, and the patient constantly operates a process of rationalization, telling herself and the operator something that closes the subject, giving a positive outlook for the future or a fatal acceptance of the present.

It is interesting to note the rigidity of the behaviour and an harnessed emotionality that is perceived as authentic only on rare occasions when the patient assumes a tone of voice and frankly childish facial expressions: such occasions are extremely circumscribed and it is difficult to connect them to specific events or situations.

\section{Psychometrics}

In the months following the crime, Alice also underwent the following tests: Graphic tests (human figure and family design) (Corman 1978; Machover 1949), Minnesota Multiphasic Personality Inventory-2 (MMPI-2) (Butcher et al. 1989), Big Five Inventory (BFI) (John and Srivastava 1999), Temperament and Character Inventory (TCI) (Cloninger et al. 1994) and Adult Attachment Interview (AAI) (George, Kaplan, and Main 1985).

\section{Graphical tests}

Subjected to the administration of graphic tests, such as drawing a human figure and a drawing of her family, the patient collaborates. The line is usually light, often fragmented, the design is not very 
accurate, the figures barely delineated, frequent blackening on the area of the head and hair. These elements confirm inhibition, self-centeredness, insecurity, introversion, emotional constraint and concern about sexual issues.

In the drawing of the human figure (Figure 1), she first draws a figure corresponding to the opposite sex: index of difficulty of sexual identification, conflict in the acceptance of one's own social-sexual roles, likely strong attachment or submission to the parent or to a person of the opposite sex.

The investigation shows that the drawings of human figures are projections of the husband and of herself, with the insertion of elements of idealization. The female figure in particular is described as selfconfident, orderly and gratified by keeping order around the household, having a job, a family, children, "at least one". Indicative is the way she underlines that the person drawn likes "to command a little of everything" even if, with the husband, "in the end there is an agreement". When asked to describe a defect, the patient complains of shyness and insufficient control of emotions. Evidently, elements of hypervigilant narcissism transpire from this, and what the clinician perceives as pathological and excessive emotional control, for the patient is the not fully functional resource, or the type of adaptation that the patient has electively chosen.

The patient was then asked to draw a family (Figure 2). The drawing consists of a father, a son, a daughter and a mother. The mother appears to be more withdrawn than the other figures.

The distance between the figures is filled by dashes that join the hands of the various characters, more evident in particular between father and son and between mother and daughter; in this case, the sketch is filled with three flowers that seem to separate rather than to unite the daughter from the mother and at the same time the mother from the rest of the nucleus. The two children appear closer and of the same size. The lady seems to perceive herself outside the family.

The centrality of the children is evident: they occupy a place among the parents, they seem to have the same sentimental value and they also appear interposed between the parental couple.

The flowers between the mother and the daughter assume a symbolic value, almost a commemorative element that celebrates and remembers the child's death, but at the same time acts as a perverse glue that separates and unites the mother to the rest of the family nucleus. In fact, the mother would have given the child these flowers that were in turn given to her by her husband, the mother gives them as she grasps that her daughter wanted them as she was also a "Miss". Disturbing questions arise in interpreting this passage, in particular the responsibility of the husband and the male regarding the need to recognize and eliminate the feminine.

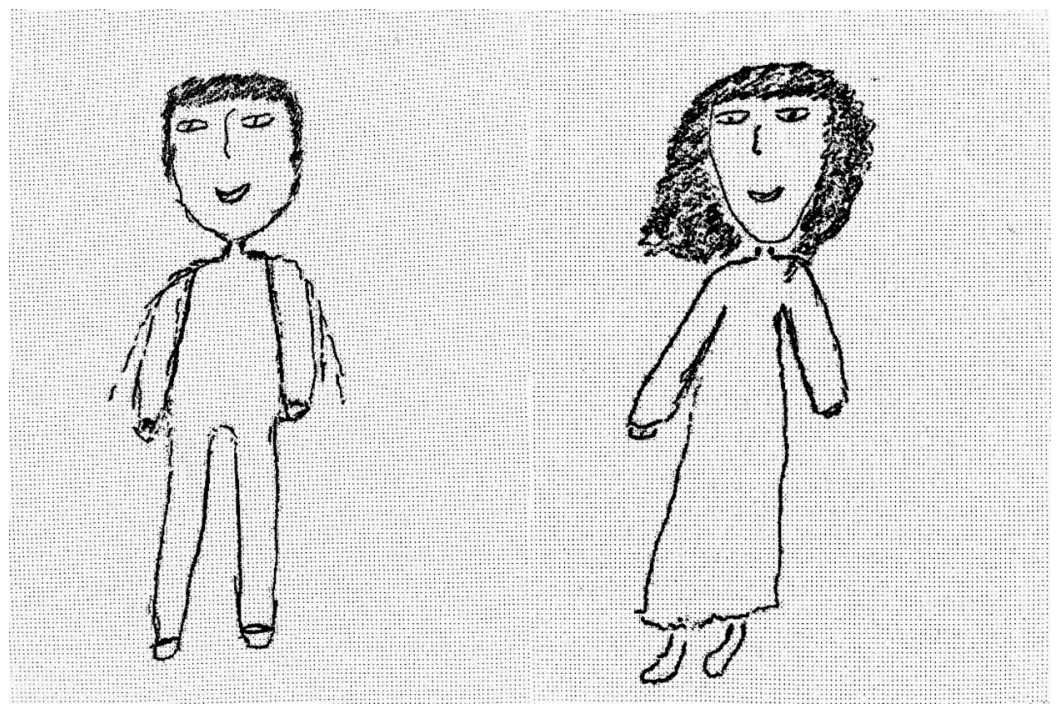

Figure 1. Drawing of the human figure. 


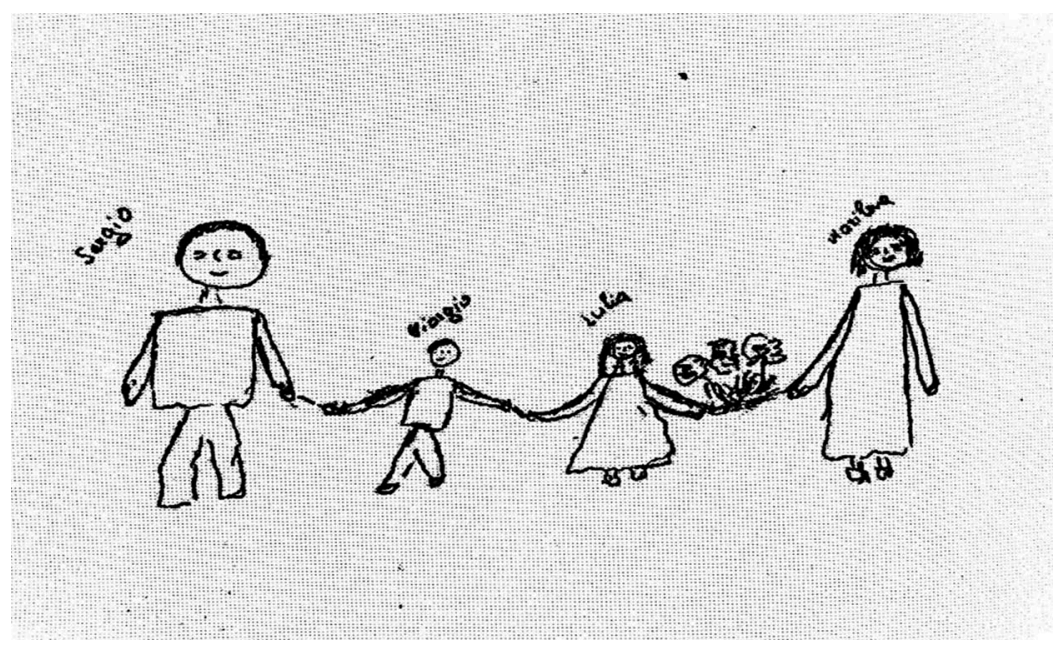

Figure 2. Drawing of the family.

\section{MMPI-2}

MMPI-2 is a standardized psychometric test of adult personality and psychopathology known as the most widely used personality measure in clinical and forensic settings (Archer et al. 2006). It consists of 567 items.

At the MMPI-2 test (Figure 3), the patient showed, at the basic and validity clinical scales, a chronic pattern of psychological maladjustment, sub-threshold in almost all scales (for probable pharmacological action) and with the only $S i$ over cut off levels. This configuration is usually associated with individuals characterized by social inhibition and avoidance, where they appear rather passive and tend to be influenced by others, especially by figures perceived as authoritarian. These traits, moreover, refer to

Minnesota Multiphasic Personality Inventory-2

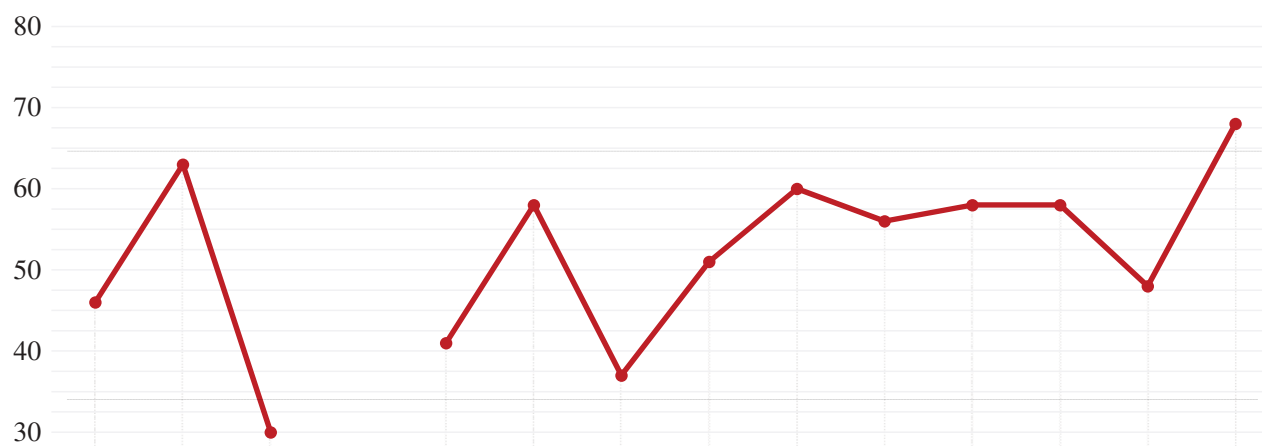

20

10

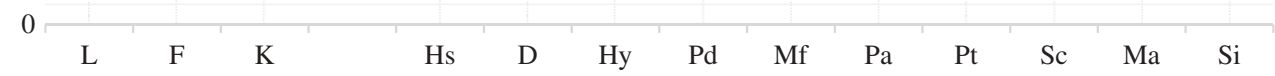

Figure 3. MMPI-2 score of the filicide women. Dotted lines represent standard range values. 
dimensions of extreme inner fragility, to a tendentially deflated mood but with the possibility of abrupt and apparently unmotivated changes, associated with the constant presence of an anxious dimension, with tension, tendency to rumination and to worry and a low self-esteem, probably because of supporting deficiencies on the part of caregivers in the developmental age. This state of inner fragility is also underlined by a particularly weak and unstructured ego system, unable to elaborate its internal conflicts and to stem the instinctual emergencies in the presence of particular stressful factors, both internal and external.

To this state of insecurity, avoidance, potential instability of a slightly deflated mood, is opposed a hostile/rabid component of considerable importance (the whole group of the External Aggressive Trends of the Content Scales turns out to be cut off). This indicates the presence of angry, aggressive and hostile components, connoted by a conception of extreme distrust in the goodness and reliability of others, perceived as moved exclusively by personal and selfish interests in interpersonal relationships. This conception would justify the components of amorality, absence of empathy and social and interpersonal alienation found out from the patient's questionnaire.

In conclusion, the profile emerged at MMPI-2 (a 2-8-7/2-7-8 code-type profile, which means the presence of a combination of scoring peaks of the content scales 2: Depression (D), 7: Psychasthenia (Pt) and 8: Schizophrenia $(\mathrm{Sc})$ ) is often associated with significant depressive syndromes with the possibility of psychotic imbalances. The fact that in this case it is below threshold allows to hypothesize the containment of the most relevant psychopathological aspects following pharmacotherapy. This structure, however, appears to be basic and subject to imbalances in case of exposure to significant stressful elements. Imbalances that, by activating the mood in a pathological sense, could easily lead to the direct expression of the hostile/rabid components mentioned above.

\section{BFI}

The BFI is a 44-items self-administered questionnaire that measures an individual on the BFI Factors (dimensions) of personality. The BFI Factors are considered as dual-personality characteristics. There is extraversion vs. introversion, agreeableness vs. antagonism, conscientiousness vs. lack of direction, neuroticism vs. emotional stability, openness vs. closeness to experience.

In the BFI test, Alice's scores are compared to the mean scores of an Italian representative sample (Fossati et al. 2011) (Figure 4). Alice got higher scores in the Extraversion, Agreeableness, Neuroticism and Openness dimensions and lower scores in the Conscientiousness dimension. More in detail, the BFI results could be interpreted as following: 1) high levels of Agreeableness and Extraversion are associated with a sympathetic and kind attitude, but also with the attempt to inhibit negative feelings trying to show a socially acceptable self-image. Highly agreeable individuals may also be able to short-circuit the cueaggression sequence (Graziano and Eisenberg 1999; Meier, Robinson, and Wilkowski 2006). 2) A high Openness score may indicate the attempt to show a healthy and functional socially acceptable self-image. 3) High level of Neuroticism may indicate in Alice the tendency to be moody, to experience emotional instability and negative emotions like anxiety, anger, frustration, envy, jealousy, guilt, depressed mood, and loneliness. Furthermore, impulsivity may often be included as a facet of Neuroticism with a lack of self-control, inattention and poorly regulated or uninhibited motor activity (Carver 2005; Ireland et al. 2015; Patton, Stanford, and Barratt 1995). Also, a low Conscientiousness score may be related to a low capacity to control impulses (McCrae and Costa 1998).

\section{$\mathrm{TCl}$}

The TCI is a 240-item inventory that operates with seven dimensions of personality traits: four temperaments (Novelty Seeking, Harm Avoidance, Reward Dependence and Persistence) and three characters (Self-Directedness, Cooperativeness and Self-Transcendence).

When the TCI test results of Alice are compared with the medium range scores of a representative Italian sample (Martinotti et al. 2008) (Figure 5), it appears that she showed low scores at the Novelty 
Big Five Inventory

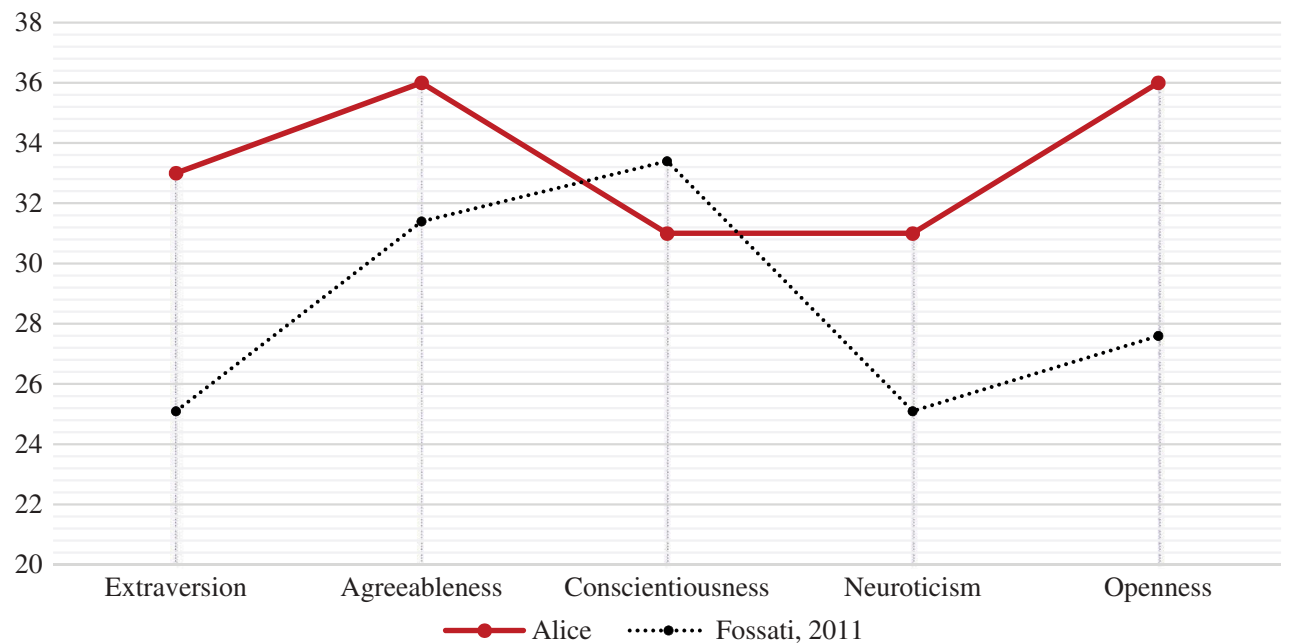

Figure 4. BFI score of the filicide woman. Dotted lines represent the mean scores of an Italian representative sample $(\mathrm{N}=318)$ (Fossati et al. 2011).

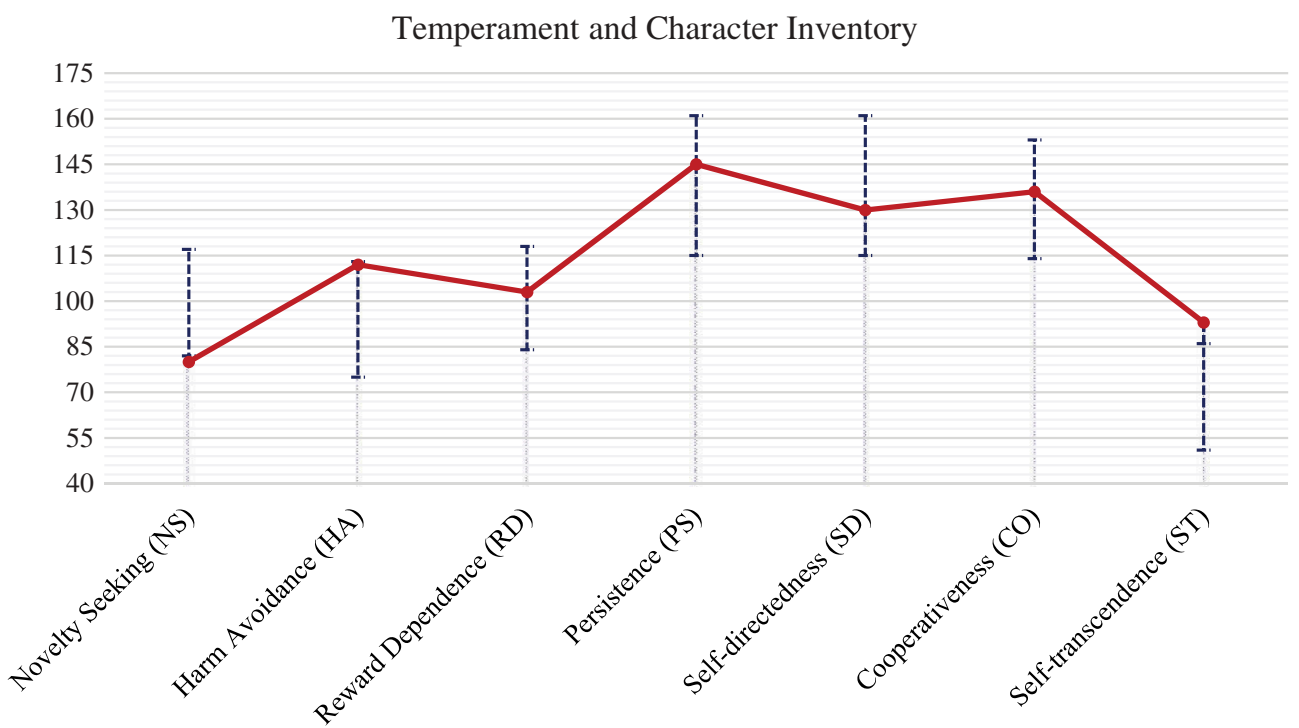

Figure 5. $\mathrm{TCl}$ score of the filicide woman. Dotted lines on each $\mathrm{TCl}$ dimensions represent the medium range scores of an Italian representative sample $(\mathrm{N}=740)$ (Martinotti et al. 2008).

Seeking and Self-directedness dimensions, and high scores at the Harm Avoidance, Persistence and Self-transcendence. Cooperativeness and Reward Dependence scores are in a medium position. Alice's TCI results may be interpreted as following: 1) low Novelty Seeking and high Harm Avoidance may indicate Alice's tendency to be charitable but also to have pessimistic worry in anticipation of future problems, passive avoidant behaviours such as fear of uncertainty and shyness facing external stressors (Cloninger et al. 1994). 2) Low Self-directedness may indicate the inability to control, regulate, and adapt behaviour to fit the situation in accord with individually chosen goals and values, showing a disorganized set of reactive impulses (Maslow 1989). 


\section{$A A I$}

The AAI is a semi-structured interview, and it is used to categorize adults' state of mind with respect to attachments. Attachments classification are: secure-autonomous (F), dismissing (D), preoccupied (E), and disoriented/disorganized (U/d). The interview consists of twenty questions focusing on early relationships with parents and the family environment.

The final classification according to main's criteria evidenced a dismissing pattern of attachment. This dismissing state of mind with respect to attachment experiences was supported by strong scores for idealization, in particular with respect to the patient's mother. The idealization of the maternal figure was not adequately backed by evidences of genuine memories of affective exchanges and by interest on the part of the mother. Furthermore, the idealization seems to widely dismiss the affective impact of separation from both parents and their neglecting attitude toward Alice. The father is described as a good parent, while being presented as always absent; the mother is described in positive terms, as a fully loving, generous and reliable parent, downplaying the extreme state of emotional unavailability due to her psychiatric illness. Overall, Alice is only able to provide with very restricted, conventional and instrumental descriptions of the exchanges and emotional experiences with her parent. For the purpose of our discussion, this attachment pattern as well as early affective experiences may be interpreted as a general disposition to shift the attention away from relevant emotional communication unavoidably brought up by the caregiving role; furthermore, the experiences of neglect may have left Alice with a scarce capability to process her babies' emotional signals. In this dismissing state of mind, the maternal may be felt as an unbearable emotional load, leaving the person with strong feelings of helplessness and inadequacy. Finally, we also contend that Alice's idealizing stance, especially toward her mother, prevented her from adequately dealing and differentiating from the traumatic identification with her mother's mental illness.

\section{Discussion}

From the history of the patient, some reflections can be attempted.

In the case just described, infanticide is the first episode of expression of a psychopathological dimension, at the age of 30 , connoted by a delusional disorder whose content, partially derivable, expresses depressive themes in which the patient feels unable to protect the children from an imminent catastrophe.

In this woman, until the born of the second child, difficulties had emerged in the sphere of relationships with others, most of them experienced as devaluing, judging, disregarding of the needs that had fueled the experiences of anger and distrust of others. Even the relationship with her husband, considered a "good" but overbearing and manipulative person, had confirmed a life of solitude and devoid of help. Besides, the primary experience had always been characterized by emotional neglect, as it is shown by the patient's mother delegation of the growth of her daughters to the grandmother for the first ten years of life. This is evident by the presence of important signs of neglect at the AAI test. A style of distancing attachment is also evident in the personality profile emerged from the tests carried out by the patient, and characterized by inhibition of the relationship and by high levels of anger, which are mostly denied, compared to a tendency to complacency and apparent willingness in the relationship (in the MMPI-2, the whole group of the External Aggressive Trends of the Content Scales is above cut off; in the BFI, higher scores in the Extraversion, Agreeableness, and, in the TCI, low Novelty Seeking and high Harm Avoidance).

It is known that motherhood is a critical moment in a woman's history. In fact, during pregnancy, a woman confronts herself regressively with her maternal model, in a sort of recapitulation with her own past that allows her identification with a mother capable of giving life, facilitating the passage of her identity from a daughter to mother, in an evolutionary dimension. On the other hand, as a result of this recapitulation, she must also be able to develop an autonomous and differentiated sense of 
identity that allows her to deal directly with the emerging needs of the new relationship with her/his daughter/son. Whereas the regression phase does not allow such a process, painful, unresolved conflicts can re-emerge in the relationship with the child, and the woman may not even have access to a sufficiently stable and solid sense of identity. In this mother, the identification with a maternal figure would seem to have emerged more clearly with the birth of the daughter, second-born, rather than in the first pregnancy. The birth of the daughter would thus have likely thrown her back into a fragile insane feminine reference model, where, to protect the children from a dangerous world, she would have to make a gesture without hope.

From what emerges from the clinical history and from the assessment tests carried out, we can hypothesize that infanticide has represented the effort to suppress some vital and redemption instances, born from the attempt to differentiate from an insane maternal model. This effort, followed by the sense of extreme loneliness that accompanied the patient for her whole life, exploded in the desperate rage of the infanticide.

Exploring a single case always requires a high level of caution in drawing general conclusions. The case of Alice may be useful to shed light on the necessity to explore personality of new mothers who show some signs of mental distress. The exploration of the attachment style can also be useful to outline a profile at risk of carrying out aggressive acts.

\section{Declaration of Conflicting Interests}

The authors declared no potential conflicts of interest with respect to the research, authorship, and/or publication of this article.

\section{Funding}

The authors received no financial support for the research, authorship, and/or publication of this article.

\section{Notes on contributors}

Nicoletta Giacchetti for many years she has worked in the acute psychiatry department of Policlinico Umberto I Hospital of Rome. She collaborates as a psychiatrist and researcher with the post-partum disorders unit of Policlinico Umberto I, interested in studying perinatal depression and mother-child relationship disorders.

Corinna Pancheri she specialized in psychiatry at La Sapienza University, Policlinico Umberto I Hospital of Rome with a dissertation about dimensional psychopathology of psychiatric outpatient's immigrants. She collaborates as a psychiatrist and researcher with the post-partum disorders unit of Policlinico Umberto I.

Riccardo Williams is a psychologist and he has been investigating the impact of early relational trauma on personality development and psychopathology.

Michela Marconi she specialized in psychiatry at Università Cattolica's Faculty of Medicine and Surgery, Agostino Gemelli General Hospital where she worked on bipolar disorders and alcohol abuse disorders. After specialization, she worked at Pontecorvo forensic psychiatric hospital looking at antisocial personality disorder and psychopathy.

Rosa Magistro she worked mainly in the field of psychiatric rehabilitation working in therapeutic communities for young people with personality disorders and in forensic psychiatric hospitals. She collaborated with schools, social services and Courts. She is interested in the diagnosis and treatment of childhood and parenthood disorders.

Luciano Pozzuoli he works on the management and development of programs for people with mental illness. He also worked as a forensic psychiatrist at the Court of Cassino. From 2015 to 2018 he was the Director of the Forensic Psychiatric Hospital for men at Ceccano and for women at Pontecorvo.

Franca Aceti psychiatrist and analyst, has gained an extensive experience in psychopathology and child-parent relationship disorders. She has been the head of the post-partum depression unit at La Sapienza University of Rome for the last 10 years. 


\section{References}

Aceti, Franca, Francesca Aveni, Valerio Baglioni, Giuseppe Mattia Carluccio, Francesco Colosimo, Nicoletta Giacchetti, Isabella Marini, Valentina Meuti, Paola Motta, Michela Zaccagni, et al. 2012a. "Perinatal and Postpartum Depression: From Attachment to Personality. A Pilot Study." Journal of Psychopathology 18:328-34.

Aceti, Franca, Giuseppe Mattia Carluccio, Valentina Meuti, Francesca Piperno, Carla Sogos, Bianca Straniero Sergio, and Sara Nicolis. 2012b. "Parental Care and Post Partum Depression: A Case Report." Rivista di psichiatria 47 (3):221-25. doi:10.1708/1128.12444.

Altshuler, Lori L., Victoria Hendrick, and Lee Cohen. 1998. "Course of Mood and Anxiety Disorders during Pregnancy and the Postpartum Period." The Journal of Clinical Psychiatry 59(Suppl 2):29-33. (http://www.ncbi. nlm.nih.gov/pubmed/9559757).

Archer, Robert P., Jacqueline K. Buffington-Vollum, Rebecca V. Stredny, and Richard W. Handel. 2006. “A Survey of Psychological Test Use Patterns among Forensic Psychologists.” Journal of Personality Assessment 87 (1):84-94. doi:10.1207/s15327752jpa8701_07.

Barone, Lavinia, Alessandra Bramante, Francesca Lionetti, and Massimiliano Pastore. 2014. "Mothers Who Murdered Their Child: An Attachment-Based Study on Filicide." Child Abuse \& Neglect 38 (9):1468-77. doi:10.1016/j. chiabu.2014.04.014.

Born, Leslie, Dawn Zinga, and Meir Steiner. 2004. "Challenges in Identifying and Diagnosing Postpartum Disorders." Primary Psychiatry 11 (3):29-36.

Bourget, Dominique, Jannifer Grace, and Laurie Whitehurst. 2007. “A Review of Maternal and Paternal Filicide.” The Journal of the American Academy of Psychiatry and the Law 35(1):74-82. (http://www.ncbi.nlm.nih.gov/pubmed/ 17389348).

Butcher, James N., Grant W. Dahlstrom, John R. Graham, Auke Tellegen, and B. Kreammer. 1989. The Minnesota Multiphasic Personality Inventory-2 (MMPI-2) Manual for Administration and Scoring. Minneapolis, MN: University of Minneapolis Press.

Camperio Ciani, Andrea S. and Lilybeth Fontanesi. 2012. "Mothers Who Kill Their Offspring: Testing Evolutionary Hypothesis in a 110-Case Italian Sample.” Child Abuse \& Neglect 36 (6):519-27. doi:10.1016/j. chiabu.2012.05.001.

Carver, Charles S. 2005. "Impulse and Constraint: Perspectives from Personality Psychology, Convergence with Theory in Other Areas, and Potential for Integration.” Personality and Social Psychology Review: an Official Journal of the Society for Personality and Social Psychology, Inc 9 (4):312-33. doi:10.1207/s15327957pspr0904_2.

Cloninger, Robert, Thomas R. Przybeck, Dragan Svrakic, and R.D. Wetzel. 1994. The Temperament and Character Inventory (TCI): A Guide to Its Development and Use. St Louis: Center for Psychology of Personality, Washington University.

Corman, Louis. 1978. Il disegno della famiglia: Test per bambini. Torino: Bollati Boringhieri.

Craig, M. 2004. "Perinatal Risk Factors for Neonaticide and Infant Homicide: Can We Identify Those at Risk?" Journal of the Royal Society of Medicine 97(2):57-61. doi:10.1177/014107680409700203.

Debowska, Agata, Daniel Boduszek, and Katie Dhingra. 2015. "Victim, Perpetrator, and Offense Characteristics in Filicide and Filicide-Suicide." Aggression and Violent Behavior 21:113-24. doi:10.1016/J.AVB.2015.01.011.

Fossati, Andrea, Serena Borroni, Donatella Marchione, and Cesare Maffei. 2011. "The Big Five Inventory (BFI)." European Journal of Psychological Assessment 27 (1):50-58. doi:10.1027/1015-5759/a000043.

Friedman, Susan H., Sarah M. Horwitz, and Phillip J. Resnick. 2005. "Child Murder by Mothers: A Critical Analysis of the Current State of Knowledge and A Research Agenda.” American Journal of Psychiatry 162 (9):1578-87. doi:10.1176/appi.ajp.162.9.1578.

Friedman, Susan H., Debra R. Hrouda, Carol E. Holden, Stephen G. Noffsinger, and Phillip J. Resnick. 2005a. "Child Murder Committed by Severely Mentally Ill Mothers: An Examination of Mothers Found Not Guilty by Reason of Insanity." Journal of Forensic Sciences 50(6):1466-71. doi:10.1520/JFS2005132.

Friedman, Susan H., Debra R. Hrouda, Carol E. Holden, Stephen G. Noffsinger, and Phillip J. Resnick. 2005 b. "Filicide-Suicide: Common Factors in Parents Who Kill Their Children and Themselves." The Journal of the American Academy of Psychiatry and the Law 33(4):496-504. (http://www.ncbi.nlm.nih.gov/pubmed/16394226).

Friedman, Susan H. and Phillip J. Resnick. 2007. "Child Murder by Mothers: Patterns and Prevention." World Psychiatr: Official Journal of the World Psychiatric Association (WPA) 6(3):137-41. (http://www.ncbi.nlm.nih. gov/pubmed/18188430).

Gale, Scott and Bernard L. Harlow. 2003. "Postpartum Mood Disorders: A Review of Clinical and Epidemiological Factors." Journal of Psychosomatic Obstetrics and Gynaecology 24(4):257-66. doi:10.3109/01674820309074690.

George, Carol, Nancy Kaplan, and Mary Main. 1985. The Adult Attachment Interview. Unpublished manuscript. Berkley: University of Carlina at Berkley.

Giacchetti, Nicoletta, Paolo Roma, Corinna Pancheri, Riccardo Williams, Valentina Meuti, and Franca Aceti. 2018. "Personality Traits in a Sample of Italian Filicide Mothers." Rivista di psichiatria 54(2). 
Graziano, William G. and Nancy H. Eisenberg. 1999. “Agreeableness as a Dimension of Personality.” Pp. 795-825 in Handbook of Personality. edited by Robert Hogan, John Johnson and Stephen Briggs. San Diego: CA: Academic Press.

Grussu, Pietro. 2012. "Neonaticide and Infanticide: Homicidal Mothers, Risk Factors and Preventive Interventions." Psicologia Clinica Dello Sviluppo 1:37-64.

Huchzermeier, Christian and Hanna Heinzen. 2015. "A Young Woman Who Killed 5 of Her Own Babies: A Case of Multiple Neonaticide.” Journal of Forensic and Legal Medicine 35:15-18. doi:10.1016/j.jflm.2015.06.016.

Ireland, Molly E., Justin Hepler, Li Hong, and Albarracín. Dolores. 2015. "Neuroticism and Attitudes toward Action in 19 Countries." Journal of Personality 83 (3):243-50. doi:10.1111/jopy.12099.

John, Oliver P. and Sanjay Srivastava. 1999. "The Big-Five Trait Taxonomy: History, Measurement, and Theoretical Perspectives." Pp. 102-38 in Handbook of Personality: Theory and Research (Vol. 2), edited by L. Pervin and O. John. New York, NY: Guilford Press,

Kendler, Kenneth S., Margaret Gatz, Charles O. Gardner, and Nancy L. Pedersen. 2006. "Personality and Major Depression: A Swedish Longitudinal, Population-Based Twin Study.” Archives of General Psychiatry 63 (10):1113. doi:10.1001/archpsyc.63.10.1113.

Lewis, Catherine F. and Scott C. Bunce. 2003. "Filicidal Mothers and the Impact of Psychosis on Maternal Filicide." The Journal of the American Academy of Psychiatry and the Law 31(4):459-70. (http://www.ncbi.nlm.nih.gov/ pubmed/14974802).

Machover, Karen. 1949. "Personality Projection in the Drawing of the Human Figure (A Method of Personality Investigation)." American lectures in psychology: Vol. 25. Springfield: Charles C Thomas Publisher.

Martinotti, Giovanni, Laura Mandelli, Marco Di Nicola, Alessandro Serretti, Andrea Fossati, Serena Borroni, C. Cloninger Robert, and Luigi Janiri. 2008. "Psychometric Characteristic of the Italian Version of the Temperament and Character Inventory-Revised, Personality, Psychopathology, and Attachment Styles." Comprehensive Psychiatry 49 (5):514-22. doi:10.1016/j.comppsych.2007.11.002.

Maslow, Abraham H. 1989. Self-Directed Behavior: Self-Modification for Personal Adjustment. $5^{\text {th }}$ ed. Pacific grove: Calif: Brooks/Cole Publishing.

McCrae, Robert R. and Paul T. Costa. 1998. “The Five-Factor Theory of Personality.” Pp. 182-207 in Handbook of Personality: Theory and Research, $3^{\text {rd }}$ ed. New York, NY: Guilford Press.

McKee, Geoffrey R. and Alessandra Bramante. 2010. "Maternal Filicide and Mental Illness in Italy: A Comparative Study." The Journal of Psychiatry \& Law 38 (3):271-82. doi:10.1177/009318531003800303.

Meier, Briam P., Michael D. Robinson, and Benjamin M. Wilkowski. 2006. "Turning the Other Cheek: Agreeableness and the Regulation of Aggression-Related Primes." Psychological Science 17 (2):136-42. doi:10.1111/j.14679280.2006.01676.x.

Meuti, Valentina, Isabella Marini, Alessandra Grillo, Marco Lauriola, Carlo Leone, Nicoletta Giacchetti, and Franca Aceti. 2014. "MMPI-2: Cluster Analysis of Personality Profiles in Perinatal Depression-Preliminary Evidence." The Scientific World Journal ID:964210, doi:10.1155/2014/964210.

Patton, Jim H., Matthew S. Stanford, and Ernest S. Barratt. 1995. "Factor Structure of the Barratt Impulsiveness Scale." Journal of Clinical Psychology 51(6):768-74. doi:10.1002/1097-4679(199511)51:6<768::AID-JCLP2270510607>3.0.CO;2-1.

Podolska, Magdalena Z., Mariola Bidzan, Mikołaj Majkowicz, Jacek Podolski, Olimpia Sipak-Szmigiel, and Elzbieta Ronin-Walknowska. 2010. "Personality Traits Assessed by the NEO Five-Factor Inventory (NEO-FFI) as Part of the Perinatal Depression Screening Program.” Medical Science Monitor: International Medical Journal of Experimental and Clinical Research 16(9):PH77-81. (http://www.ncbi.nlm.nih.gov/pubmed/20802425).

Porter, Theresa and Helen Gavin. 2010. "Infanticide and Neonaticide: A Review of 40 Years of Research Literature on Incidence and Causes." Trauma, Violence, \& Abuse 11 (3):99-112. doi:10.1177/1524838010371950.

Putkonen, Hanna, Jutta Collander, Marja-Liisa Honkasalo, and Lönnqvist Jouko. 1998. "Finnish Female Homicide Offenders 1982-92.” The Journal of Forensic Psychiatry 9(3):672-84. doi: 10.1080/09585189808405381.

Resnick, Phillip J. 1969. “Child Murder by Parents: A Psychiatric Review of Filicide.” American Journal of Psychiatry 126 (3):325-34. doi:10.1176/ajp.126.3.325.

Resnick, Phillip J. 1970. "Murder of the Newborn: A Psychiatric Review of Neonaticide." American Journal of Psychiatry 126 (10):1414-20. doi:10.1176/ajp.126.10.1414.

Riecher-Rössler, Anita and Maria Hofecker Fallahpour. 2003. "Postpartum Depression: Do We Still Need This Diagnostic Term?” Acta Psychiatrica Scandinavica 108(418):51-56. doi:10.1034/j.1600-0447.108.s418.11.x.

Şar, Vadat, Aydın Nazan, Onno van der Hart, A. Frankel Steven, Meriç Şar, and Oğuz Omay. 2017. “Acute Dissociative Reaction to Spontaneous Delivery in a Case of Total Denial of Pregnancy: Diagnostic and Forensic Aspects." Journal of Trauma \& Dissociation 18 (5):710-19. doi:10.1080/15299732.2016.1267685.

Spinelli, Margaret G. 2001. “A Systematic Investigation of 16 Cases of Neonaticide.” American Journal of Psychiatry 158 (5):811-13. doi:10.1176/appi.ajp.158.5.811.

UNICEF. 2003. Annual report.

Wolkind, Stephen, Elisabeth M. Taylor, Alison J. Waite, Madeline Dalton, and J. L. Emery. 1993. "Recurrence of Unexpected Infant Death." Acta Paediatrica (Oslo, Norway : 1992) 82(10):873-76. doi:10.1111/j.1651-2227.1993. tb12583.x. 